\title{
Towards a national 3D geological model of Denmark
}

\author{
Peter B.E. Sandersen, Thomas Vangkilde-Pedersen, Flemming Jørgensen, Richard Thomsen, Jørgen \\ Tulstrup and Johnny Fredericia
}

As part of its strategy, the Geological Survey of Denmark and Greenland (GEUS) is to develop a national, digital 3D geological model of Denmark that can act as a publicly accessible database representing the current, overall interpretation of the subsurface geology. A national model should be under constant development, focusing on meeting the current demands from society. The constant improvements in computer capacity and software capabilities have led to a growing demand for advanced geological models and 3D maps that meet the current technical standards (Berg et al. 2011). As a consequence, the users expect solutions to still more complicated and sophisticated problems related to the subsurface. GEUS has a long tradition of making 2D maps of subsurface layer boundaries and near-surface geology (Fredericia \& Gravesen 2014), but in the change from $2 \mathrm{D}$ to $3 \mathrm{D}$ and when combining data in new ways, new geological knowledge is gained and new challenges of both technical and organisational character will arise. The purpose of this paper is to present the strategy for the national 3D geological model of Denmark and the planned activities for the years ahead. The paper will also reflect on some of the challenges related to making and maintaining a nationwide 3D model. Initially, the model will only include the Danish onshore areas, with the Danish offshore areas and Greenland to be added later using a similar general setup.

\section{The elements of the national 3D geological model}

The national model will be constructed as a $3 \mathrm{D}$ geological framework model consisting of a number of surfaces. These surfaces can represent top and bottom of defined geological formations, stratigraphic complexes or other types of spatially recognisable units, as well as erosional surfaces, stratigraphic markers or transgressional surfaces. The surfaces will characterise units defined in a legend of the Danish subsurface compiled in connection with the national 3D geological model project. Interpretation points, lines, polygons, etc. will define the surfaces together with an interpolated or triangulated grid. This framework model is planned to grow continually with the addition of new surfaces. The layered framework model will be supplemented by volumetric cells containing detailed geological information between mapped surfaces (Fig. 1). Lithology and lithofacies or related parameters, such as porosity or resistivity, can be added as attributes to the cells.

The model is intended to contain varying levels of detail and it will be possible to use the model at different scales. The users will be able to download the exact elements they require for a specific modelling purpose within a particu-

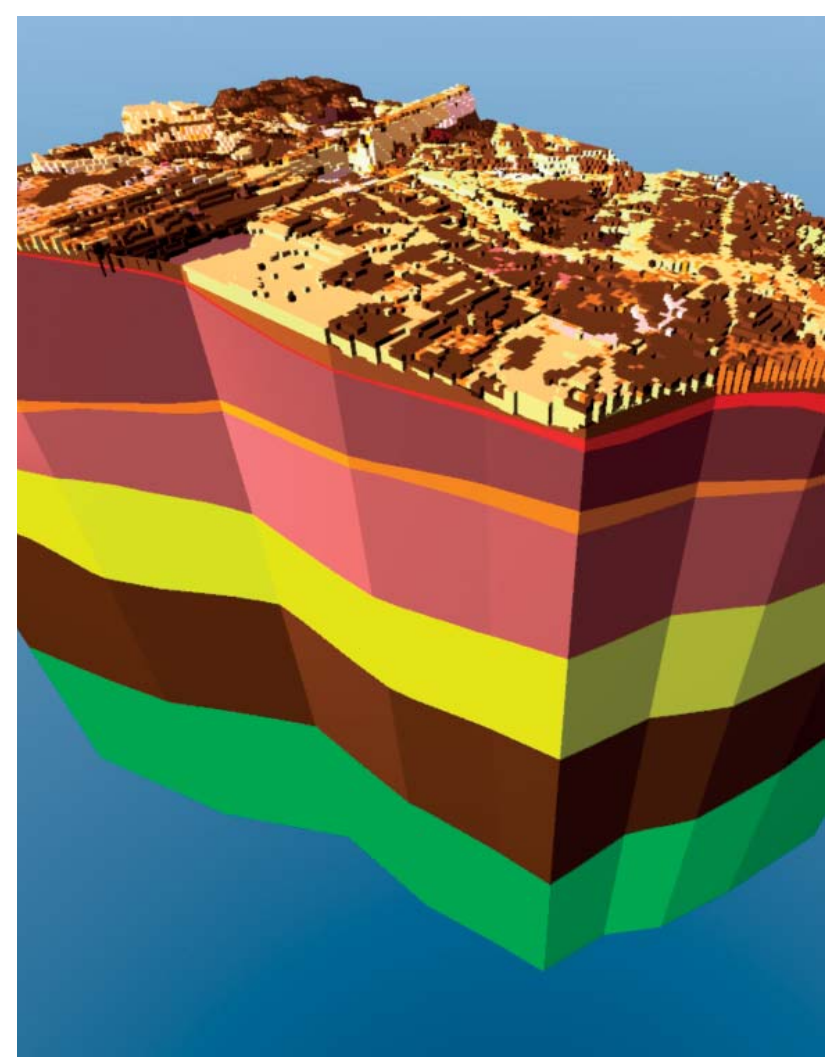

Fig. 1. Model example combining layers and volumetric cells. The manmade layers in the uppermost part of the subsurface are represented as volumetric pixels (voxels), and the deeper parts of the succession as layers. Based on the 3D model of the municipality of Odense (Mielby et al. 2015). 
lar area, i.e. near-surface layers for further hydrogeological modelling in connection with groundwater resource management. This will, of course, require guidance regarding the scale in which the extracted model element can be used. Standards and procedures will be developed for the construction of the model elements as well as for performing quality assurance, quality assessment and model updates. The national model is planned to be platformindependent and by using standardised import and export formats, the construction of model elements will therefore not be restricted to specific modelling software packages.

The model will initially contain a number of key surfaces, but details will continuously be added. At present, a number of surfaces encompassing the deep succession from top pre-Zechstein to the top of the Chalk Group exist in preliminary versions (Table 1). Above this part of the succession, construction of 1-2 major Tertiary surfaces and the top of the pre-Quaternary surface is planned. Modelling of the complex Quaternary geology will be done locally and regionally by using layer boundaries and volumetric cells. Because the amount of dated Quaternary sediments in Denmark is limited these model elements will not necessarily be modelled as specific litho- or chronostratigraphic units, but as units solely defined by lithology.

The model database constitutes an important part of the national 3D geological model containing all the required model elements while at the same time being sufficiently flexible when future elements are added.

\section{Use of existing data and geological models}

GEUS hosts a wide range of publicly accessible databases (e.g. Ditlefsen et al. 2012; Hansen \& Pjetursson 2011; Møller et al. 2009a, b; Tulstrup 2004). The most significant databases are the Jupiter well database, the geophysical database GERDA, the oil and gas database FRISBEE and the Geological Models Database. These databases will constitute the main data supply for the national 3D geological model, and therefore their continuous update is very important. The incorporation into the national $3 \mathrm{D}$ geological model will ensure that the vast amount of data collected over more than a century is continually used and updated.

In Denmark, 2D and 3D geological mapping and modelling have been performed regionally and locally primarily by GEUS, universities, regional authorities and municipalities, oil companies, the mining industry and consulting companies. Models have typically been made in connection with oil and gas exploration, groundwater and drinking water projects, geothermal projects, raw material and mineral exploration as well as soil and groundwater contamination issues. Especially the intensive groundwater mapping campaign over the past 15 years has produced a large number of publicly available models for the upper parts of the subsurface (Thomsen et al. 2013). This has resulted in a patchwork of 2D and 3D models, but because the models have been built in different ways they are difficult to merge. Therefore, in the process of making a new national 3D geological model it is necessary to evaluate and amend the existing models.

The national 3D geological model will be dynamic and regularly updated in order to include new data and interpretations. The modelling will therefore follow strict versioning procedures, with options for displaying the data on which updated interpretations are based.

\section{Model uncertainties, quality assurance and quality control}

Handling of model uncertainty has been discussed intensely for many years and many different suggestions have been put forward (e.g. Lark et al. 2014; Sandersen 2008; Tacher et al. 2006; Wellmann et al. 2014). The change from 2D to $3 \mathrm{D}$ and the ensuing increased model complexity will create a demand from users for assessment of the inherent uncertainty of the model. This issue is highly complex and the challenges are numerous. The uncertainty of a geological model will be a mixture of the uncertainties of each dataset and the uncertainties of the interpretations of the combined dataset, with the additional challenge of handling both the quantitative and the qualitative aspects.

Table 1. Planned main surfaces in the national 3D geological model

\begin{tabular}{lcc}
\hline Model element & Surface & Period \\
\hline Pre-Quaternary succession & Top & Neogene and older \\
\hline Palaeogene succession & Top & Palaeogene \\
\hline Chalk Group & $\begin{array}{c}\text { Top } \\
\text { Bottom }\end{array}$ & Cretaceous \\
\hline Frederikshavn Formation & $\begin{array}{c}\text { Top } \\
\text { Bottom }\end{array}$ & Cretaceous/Jurassic \\
\hline Haldager Sand Formation & $\begin{array}{c}\text { Top } \\
\text { Bottom }\end{array}$ & Jurassic \\
\hline Fjerritslev Formation & $\begin{array}{c}\text { Top } \\
\text { Bottom }\end{array}$ & Jurassic \\
\hline Gassum Formation & $\begin{array}{c}\text { Top } \\
\text { Bottom }\end{array}$ & Triassic \\
\hline Bunter Sandstone Formation & $\begin{array}{c}\text { Top } \\
\text { Bottom }\end{array}$ & Triassic \\
\hline Zechstein Group & $\begin{array}{c}\text { Top } \\
\text { Bottom }\end{array}$ & Zechstein \\
\hline
\end{tabular}


Fig. 2. Cross-section sketch illustrating the challenges of modelling in areas with low data density. Vertical rods represent boreholes with clay (orange) and sand (red). Coloured background in the area with high data density shows measured and gridded sediment resistivity values (TEM data; Transient ElectroMagnetic method). Red and purple: high resistivities. Green and blue: low resistivities.

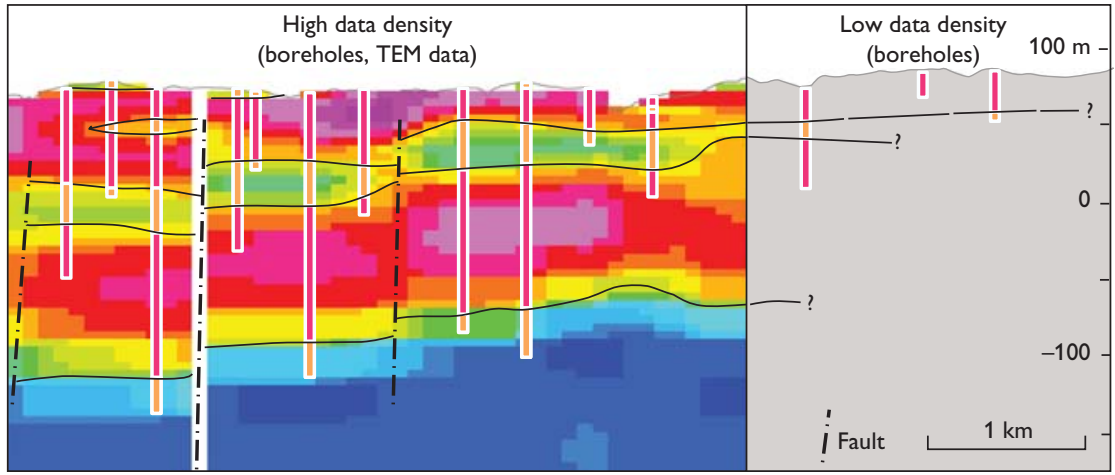

A concept for assessing the uncertainties of the individual model elements will be made specifically for the national 3D geological model to ensure that all model elements are evaluated in the same way. The uncertainty concept will not necessarily be adaptable for use in models other than the national 3D geological model, because it will be tailored specifically to the chosen model setup.

The national 3D geological model will be disseminated to a variety of users and therefore a transparent construction process and a thorough documentation are required. Descriptions of workflows, procedures and guidelines for quality assurance and quality control will be handled by an editorial function in order to keep up a high degree of consistency.

\section{Discussion}

In general, varying data coverage and data resolution pose a major challenge for the construction of the national 3D geological model. In the deep parts of the subsurface (below 300-400 m) the data are primarily from boreholes and seismic surveys carried out by the oil and gas industry and with a coverage dictated by the focus of the exploration surveys. In the shallow parts of the subsurface, the data are primarily collected in connection with groundwater investigations, raw material or mineral exploration, soil contamination investigations and geotechnical projects. Data originate from boreholes, seismic surveys, electric and electromagnetic surveys and outcrops. Generally the data density is much higher than in the deeper parts of the subsurface. The shallow part of the Danish subsurface is greatly affected by Pleistocene glaciations. This part is therefore particularly lithologically and structurally complex and requires a large amount of detailed input data.

Even though the data density is rather high in the uppermost parts of the subsurface, the data are in fact often geographically clustered. Therefore, in many areas detailed modelling can only be made within such data clusters. In reality, the result is a patchwork of areas with a high data density in the survey focus areas and a low density in the surrounding areas. This means that the varying data density will be reflected in the geological model interpretations resulting in certain geological elements not being resolved outside the data clusters (Fig. 2). This challenge can be met by constructing a model that can handle different scales with different degrees of detail, but not necessarily with a full geographical coverage of the most detailed interpretations. A model like this will display the actual status of the mapping and show where the geological knowledge is good and where not. In modern 3D modelling software there are no zoom limitations, and if not otherwise stated, the data and the interpreted model can be viewed and evaluated at any scale. It is therefore important to convey the scalerelated limitations of the model to the users.

The potential users of the national 3D geological model are numerous (i.e. waterworks, municipalities, governmental agencies, raw-materials and minerals industry, private consultants and educational institutions), and they will have a variety of purposes for their use of the downloaded model elements. To cater for as many of these as possible, the model will be constructed as a multi-purpose tool. This means that the output from the model will require standardised, off-the-shelf products as well as individually tailored elements based on the same framework. An example of a standardised product from the ' $3 \mathrm{D}$ model department store' could be a suite of nation-wide, fixed-scale surfaces to be used in projects dealing with regional or national assessments. A tailored product from the '3D custom shop', on the other hand, could be the delivery of a number of specific surfaces in a selected area supplied with lithological information in volumetric cells to be used in a geographically small-scale project. In this way the 3D model construction procedures can be kept stringent, while the model output can be more flexible in order to meet specific user needs. 


\section{Summary and perspectives}

The national 3D geological model of Denmark will be constructed from the geological and geophysical data collected during decades of surveying. It will also be based on existing 2D maps and geological models, from which specific elements will be extracted and incorporated. All basic data used in the national $3 \mathrm{D}$ geological model are stored in an array of GEUS databases. The model will be dynamic and continuously updated in order to maintain relevance and appeal to the end users. The model will provide a wide range of end users with standardised model downloads as well as with tailor-made products.

Building a national $3 \mathrm{D}$ geological model for the country will require a considerable effort over a long period and therefore the model is planned to start with only a limited number of key elements. It will then continue to grow and in the process seek to adapt to the varying demands from society. The short-term strategy is to establish at least 15 key surfaces within the next four years and initiate construction of regional and local geological elements in the shallow parts of the model. The model databases and a beta-version of the web interface will be established and launched. In addition, standards and procedures related to the construction of the $3 \mathrm{D}$ model will be described in a series of guidelines. The long-term strategy is to include local and regional surfaces of the main surveyed areas in the national model within the next 10 years, including the Danish offshore areas.

An established dialogue with potential users throughout the process will help target the model contents towards a versatile national model that meets the requirements of the public and at the same time secures the use of the huge amount of valuable data collected over several decades.

\section{Acknowledgements}

The authors would like to thank the large number of geologists who have contributed to and participated in the workshops and discussion groups during the initial phases of the work on the national $3 \mathrm{D}$ geological model.

\section{References}

Berg, R.C., Mathers, S.J., Keefer, D.A. \& Kessler, H. (eds) 2011: A synopsis of current three-dimensional geological mapping and modeling in Geological Survey Organizations. Illinois State Geological Survey open file report, Circular 578, 2011.

Ditlefsen, C., Gausby, M., Salomonsen, J. \& Hansen, M. 2012: Vejledning i anvendelse af Modeldatabasen. Geovejledning 9, GEUS Special publication. $31 \mathrm{pp}$.

Fredericia, J. \& Gravesen, P. 2014: 125 years of geological research for society. Geological Survey of Denmark and Greenland Bulletin 31, 9-14.

Hansen, M. \& Pjetursson, B. 2011: Free, online Danish shallow geological data. Geological Survey of Denmark and Greenland Bulletin 23, 53-56.

Lark, R.M., Thorpe, S., Kessler, H. \& Mathers, S.J. 2014: Interpretative modelling of a geological cross section from boreholes: sources of uncertainty and their quantification. Solid Earth 5, 1189-1203.

Mielby, S. et al. 2015: Udvikling af en 3D geologisk/hydrogeologisk model som basis for det urbane vandkredsløb. Syntese rapport. Geological Survey of Denmark and Greenland Special publication (in Danish only).

Møller, I., Søndergaard, V. H., Jørgensen, F. Auken, E. \& Christiansen, A.V. 2009a: Integrated management and utilization of hydrogeophysical data on a national scale. Near Surface Geophysics 7, 647-659.

Møller, I., Søndergaard, V.H. \& Jørgensen, F. 2009b: Geophysical methods and data administration in Danish groundwater mapping. Geological Survey of Denmark and Greenland Bulletin 17, 41-44.

Sandersen, P.B.E. 2008: Uncertainty assessment of geological models - a qualitative approach. In: Refsgaard, J.C. et al. (eds): Calibration and reliability in groundwater modelling: credibility of modelling. International Association of Hydrological Sciences Publication 320, 345-349.

Tacher, L., Pomian-Srzednicki, I. \& Parriaux, A. 2006: Geological uncertainties associated with 3-D subsurface models. Computers \& Geosciences 32, 212-221.

Thomsen, R., Sondergaard, V. \& Klee, P. 2013: Greater water security with groundwater - Groundwater mapping and sustainable groundwater management. The Rethink Water network and Danish Water Forum white papers, Copenhagen. Available at www.rethinkwater.dk.

Tulstrup, J. 2004: Environmental data and the Internet: openness and digital data management. Geological Survey of Denmark and Greenland Bulletin 4, 45-48.

Wellmann, F.J., Lindsay, M., Poh, J. \& Jessell, M. 2014: Validating 3-D structural models with geological knowledge for improved uncertainty evaluations. Energy Procedia 59, 374-381.

\footnotetext{
Authors' address

Geological Survey of Denmark and Greenland, Øster Voldgade 10,DK-1350 Copenhagen K, Denmark; E-mail: psa@geus.dk
} 